\title{
Changes in Microbial Biomass after Continuous Application of Azolla and Rice Straw in Soil
}

\author{
Abul Kalam Mohammad Azmal ${ }^{1}$, Takuya Marumoto, Haruo Shindo, \\ and Masaya Nishiyama
}

Faculty of Agriculture, Yamaguchi University, Yoshida 1677-1, Yamaguchi, 753 Japan

Received July 17, 1996; accepted in revised form March 3, 1997

\begin{abstract}
A model experiment was conducted under tropical conditions with a view to evaluating the changes in microbial biomass and nutrient dynamics in upland soil through the continuous application of azolla and rice straw $\left(2 \mathrm{~g} \mathrm{C} \mathrm{kg}^{-1}\right.$ soil per each application). Flush decomposition of $\mathrm{C}$ was observed immediately after each application and the rate of mineralization did not change appreciably during this period. After flush decomposition, the rate of $\mathrm{C}$ mineralization from azolla was higher than that from rice straw until 9 to 13 weeks after each application and thereafter the mineralization rate was similar. The amount of inorganic $\mathrm{N}$ released from azolla increased following each application, whereas inorganic $\mathrm{N}$ in rice straw plot was immediately immobilized and the rate of immobilization increased until the 3rd application and did not increase further after the 4th application. The amounts of biomass $\mathrm{C}$ and $\mathrm{N}$ increased immediately after residue incorporation, reached the maximum level one week after each application and declined thereafter. Maximum biomass formation increased until the 2nd application and then the level remained constant. Maximum biomass $\mathbf{N}$ formation was higher in azolla than in rice straw after the 1st application, but after repeated applications, the difference became less pronounced. Continuous increase in biomass in a certain week after each application was observed, probably because of the cumulative effects of the previous applications. The increase suggests that continuous application of organic materials may enable to improve the amount of soil microbial biomass.
\end{abstract}

Key Words: azolla, $\mathrm{C}$ and $\mathrm{N}$ mineralization, continuous application, microbial biomass, rice straw, tropical soil fertility.

Microbial biomass has been used as an index of soil fertility (Marumoto 1984; Hassink et al. 1991). Available nutrients for plants are mostly derived from the soil microbial biomass, and the amount of microbial biomass and microbial activities depend on the supply of organic materials (O.M.) in soil. Therefore, regular addition of O.M. to soil is essential for the maintenance and improvement of soil fertility. However, soils in the tropical region such as in Bangladesh are not regularly amended with a sufficient amount of O.M. Moreover, the turnover rate of organic matter in tropical soils is higher than in temperate soils due to the high temperature and variable moisture level (Killham 1994). The contents

\footnotetext{
${ }^{1}$ Present address: Bangladesh Rice Research Institute, Gazipur 1701, Bangladesh.
} 
of organic $\mathrm{C}$, microbial biomass, and available plant nutrients in the Bangladesh soils were significantly lower than those in the temperate soils where intensive agriculture is practiced (Haider et al. 1991).

One possible method to increase and maintain soil fertility is the continuous application of a sufficient amount of O.M. before cultivation. Kai et al. (1984) followed the changes in the numbers of soil microorganisms after five applications of rice straw in a laboratory experiment and reported that the numbers of bacteria and fungi increased during the initial few applications and thereafter reached constant levels. In such repeated applications, not only the quantity and frequency of application but also the quality of added O.M. should influence the amount of microbial biomass and nutrient availability in soils.

Changes in microbial biomass following the application of various kinds of O.M. were reported previously by Aoyama and Nozawa (1993). Recently, in two model experiments, we have also determined the pattern of $\mathrm{C}$ and $\mathrm{N}$ mineralization and changes in microbial biomass in soils amended with plant residues such as azolla, water hyacinth, dhaincha, cowpea, sunhemp, and rice straw (Azmal et al. 1996a, b). Among them, azolla and rice straw are the most common sources of O.M. in tropical areas and they display a very low and high $\mathrm{C} / \mathrm{N}$ ratio, respectively. Therefore, in these studies, we selected them as organic additives and evaluated the effects of continuous application on the behavior of microbial biomass and nutrient dynamics in a laboratory experiment under tropical upland conditions.

\section{MATERIALS AND METHODS}

Soil. Soil used in this experiment was collected in 1995 from the upland field of Yamaguchi University Farm. Collected soil samples were partially air-dried, passed through a $2 \mathrm{~mm}$ mesh sieve and preincubated in polythene bags for 3 weeks at $20^{\circ} \mathrm{C}$. The physicochemical characteristics of the soil are listed in Table 1 . The soil was classified as red yellow soil.

Treatments and application methods of azolla and rice straw in soil. Azolla and rice straw were applied in soils one, two, three, or four times of 6-week intervals (Fig. 1). The chemical characteristics of azolla and rice straw are shown in Table 2. For each application, azolla or rice straw containing $40 \mathrm{mg} \mathrm{C}$ was applied in $20 \mathrm{~g}$ soil (oven-drybasis).

Incubation procedure. Moist soil samples equivalent to $20 \mathrm{~g}$ oven-dried soil were

Table 1. Physico-chemical characteristics of the soil used.

$\begin{array}{lc}\text { Particle size analysis: } & \\ \text { \% sand } & 53.0 \\ \text { \% silt } & 26.5 \\ \text { \% clay } & 20.5 \\ \text { Texture } & \text { Clay loam } \\ \mathrm{pH}\left(\mathrm{H}_{2} \mathrm{O}\right) & 5.10 \\ \text { Organic C }\left(\mathrm{g} \mathrm{kg}^{-1}\right) & 22.0 \\ \text { Total N }\left(\mathrm{g} \mathrm{kg}^{-1}\right) & 2.40 \\ \text { Mineral N }\left(\mathrm{mg} \mathrm{kg}^{-1}\right) & 18.0 \\ \left.\mathrm{CEC} \mathrm{(cmol}(+) \mathrm{kg}^{-1}\right) & 16.0 \\ \text { Biomass-C }\left(\mathrm{mg} \mathrm{kg}^{-1}\right) & 180 \\ \text { Biomass-N }\left(\mathrm{mg} \mathrm{kg}^{-1}\right) & 45.0\end{array}$




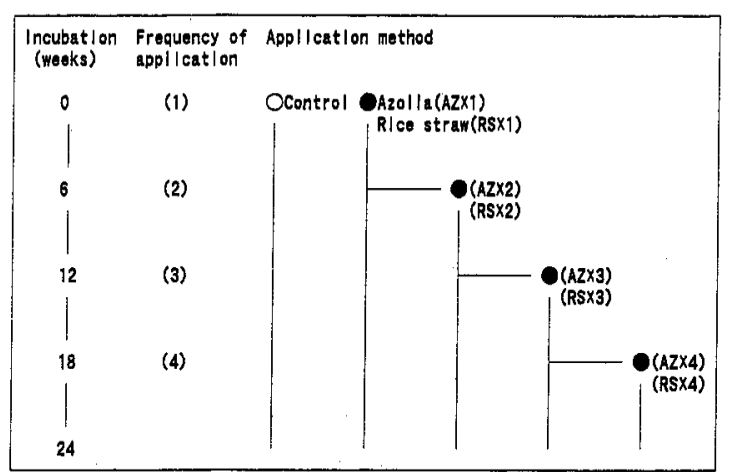

Fig. 1. Treatments and methods of application of azolla and rice straw $(0$, no addition; addition).

Table 2. Chemical properties of the plant residues used.

\begin{tabular}{lcccccr}
\hline Plant residue & $\begin{array}{c}\mathrm{T}-\mathrm{C} \\
\left(\mathrm{g} \mathrm{kg}^{-1}\right)\end{array}$ & $\begin{array}{c}\mathrm{T}-\mathrm{N} \\
\left(\mathrm{g} \mathrm{kg}^{-1}\right)\end{array}$ & $\begin{array}{c}\mathrm{C} / \mathrm{N} \\
\text { ratio }\end{array}$ & $\begin{array}{c}\text { Hexoses }^{\mathrm{b}} \\
\left(\mathrm{g} \mathrm{kg}^{-1}\right)\end{array}$ & $\begin{array}{c}\text { Hemicellulose } \\
\left(\mathrm{g} \mathrm{kg}^{-1}\right)\end{array}$ & $\begin{array}{c}\text { Cellulose }^{\mathrm{b}} \\
\left(\mathrm{g} \mathrm{kg}^{-1}\right)\end{array}$ \\
\hline Azolla (Azolla pinnata) & 340 & 33.2 & 10.2 & 30.0 & 81 & 30 \\
Rice straw (Oryza sativa) & 420 & 7.0 & 60.0 & 19.1 & 233 & 272 \\
\hline
\end{tabular}

${ }^{\mathrm{a}}$ Scientific name of plant residue is indicated in parenthesis. ${ }^{\mathrm{b}}$ These organic components were analyzed by the method of Kanke (1987).

weighed in $200 \mathrm{~mL}$ flasks for the determination of $\mathrm{N}$ mineralization and amounts of biomass $\mathrm{C}$ and $\mathrm{N}$; and in $250 \mathrm{~mL}$ bottles with plugs for measuring the amount of $\mathrm{CO}_{2}-\mathrm{C}$ evolved. Subsequently, the soils were amended with ground organic materials containing $40 \mathrm{mg} \mathrm{C}$ and the moisture content of the soils was adjusted to $60 \%$ of the maximum water holding capacity. The mouths of the $200 \mathrm{~mL}$ flasks were closed with aluminum foil and the $250 \mathrm{~mL}$ bottles were closed with plugs having two openings. The flasks and bottles containing samples were incubated up to a maximum period of 24 weeks at $30^{\circ} \mathrm{C}$ (average tropical temperature). Mineralization of $\mathrm{C}$ and $\mathrm{N}$ and amounts of biomass $\mathrm{C}$ and $\mathrm{N}$ were determined periodically. During the incubation, azolla and rice straw were added to soils according to the treatments. The flasks and the bottles were weighed at the time of each measurement and the weight loss was compensated by the addition of water to maintain a constant moisture level throughout the incubation period. For each treatment, incubation was carried out in triplicate.

Measurement of $\mathbf{C}$ and $\mathrm{N}$ mineralization. The amount of $\mathrm{CO}_{2}$ evolved during the incubation was measured according to the method described by Marumoto et al. (1974). After measurement of $\mathrm{CO}_{2}$ the samples were returned to the incubator, and the same samples were measured periodically in a similar way. For measuring $\mathrm{N}$ mineralization the samples in the flasks were extracted with a $0.5 \mathrm{M} \mathrm{K}_{2} \mathrm{SO}_{4}$ solution (soil: $\mathrm{K}_{2} \mathrm{SO}_{4}$ solution=1:5) and the amount of inorganic $\mathrm{N}\left(\mathrm{NH}_{4}{ }^{+}+\mathrm{NO}_{3}{ }^{-}\right)$was determined by the steam distillation procedure with $\mathrm{MgO}$ and Devarda's alloy (Bremner 1965). The amounts of mineralized or immobilized $\mathrm{N}$ from added O.M. were calculated by subtracting the amounts of inorganic $\mathrm{N}$ in control soil from those in amended soils.

Measurement of biomass $\mathbf{C}$ and $\mathbf{N}$. The chloroform fumigation-extraction method described by Vance et al. (1987) and Brookes et al. (1985a, b) was adopted to measure the amount of microbial biomass $\mathrm{C}$ and $\mathrm{N}$ in soils, respectively. 


\section{RESULTS AND DISCUSSION}

\section{C mineralization pattern}

Figure 2 shows that the amounts of $\mathrm{CO}_{2}-\mathrm{C}$ evolved from azolla and rice straw-treated soils were significantly larger than those from the control soil (unamended soil). A flush decomposition of $\mathrm{C}$ was observed immediately after each incorporation of O.M. and the amounts of $\mathrm{CO}_{2}-\mathrm{C}$ during the flush decomposition were similar in the azolla and rice straw-treated soils (Fig. 2). After the flush decomposition, the rate of $\mathrm{C}$ mineralization was higher in azolla than in rice straw until 9 to 13 weeks after each application (Fig. 3), presumably because the amount of easily decomposable substances such as hexoses and proteins was higher in azolla than in rice straw (Table 2). Thereafter, the rate of mineralization in the azolla and rice straw-treated soils became similar.

\section{$\mathrm{N}$ mineralization pattern}

The amount of inorganic $\mathrm{N}$ released in the azolla-treated soils increased regularly through the continuous application of azolla (Fig. 4), whereas in the rice straw-treated soil

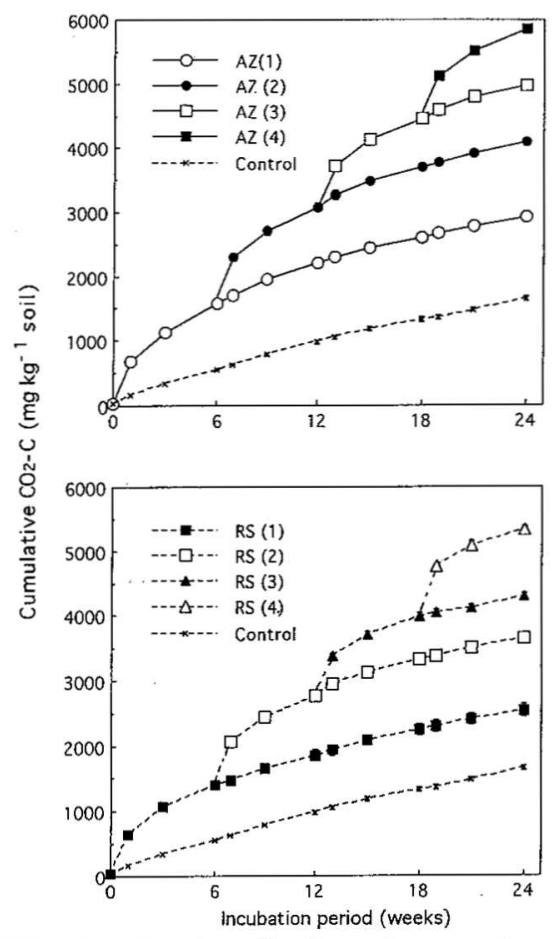

Fig. 2. C mineralization after continuous application of azolla and rice straw in soil. $\mathrm{AZ}=$ azolla, $\mathrm{RS}=$ rice straw. The numbers (1), (2), (3), and (4) indicate the frequency of application of azolla and rice straw. Standard errors are indicated by bars or within each symbol.

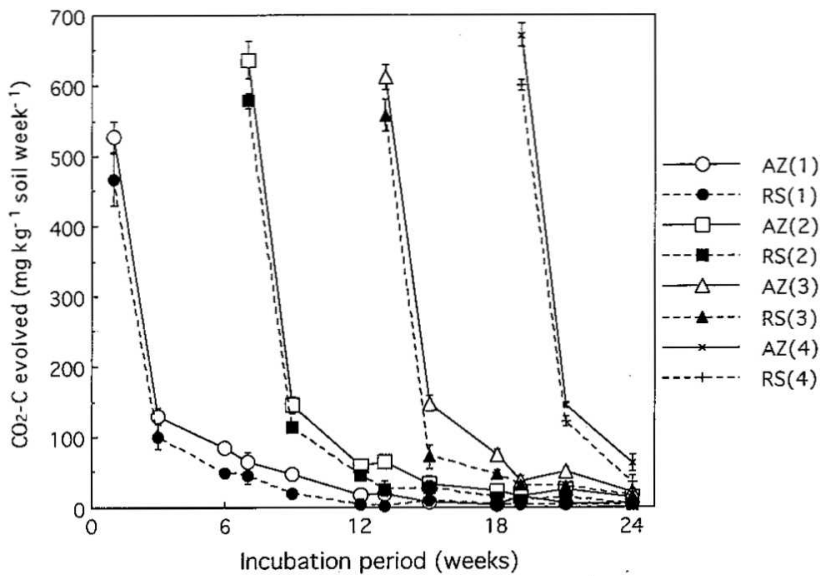

Fig. 3. Rate of $\mathrm{C}$ mineralization of azolla and rice straw. C mineralization rate was calculated by subtracting the amounts of $\mathrm{CO}_{2}-\mathrm{C}$ evolved in the control soil from those evolved in the amended soils. $\mathrm{AZ}=$ azolla, $\mathrm{RS}=$ rice straw. The numbers (1), (2), (3), and (4) indicate the frequency of application of azolla and rice straw. Standard errors are indicated by bars or within each symbol. 
inorganic $\mathrm{N}$ was immobilized immediately after each application. The mineralization-immobilization process normally depends on the C/N ratio of the added O.M. (Black 1968; Hirose 1973; Frankenberger and Abdelmagid 1985; Azmal et al. 1996a). Mineralization observed in the azolla-treated soils and immobilization in the rice straw-treated soils were due to their low and high $\mathrm{C} / \mathrm{N}$ ratios, respectively.

In the rice straw-treated soil, the immobilization increased until the 3rd application and did not increase further in the 4th application (Fig. 5). The possible reasons for the decrease in immobilization after the 4th application of rice straw are as follows; i) by repeated application of rice straw, a portion of organic $\mathrm{N}$ remained undecomposed and gradually accumulated in soil, ii) rate of remineralization of the immobilized $\mathrm{N}$ was higher after the 4th application, iii) the occurrence of maximum immobilization is limited in soil. In fact,
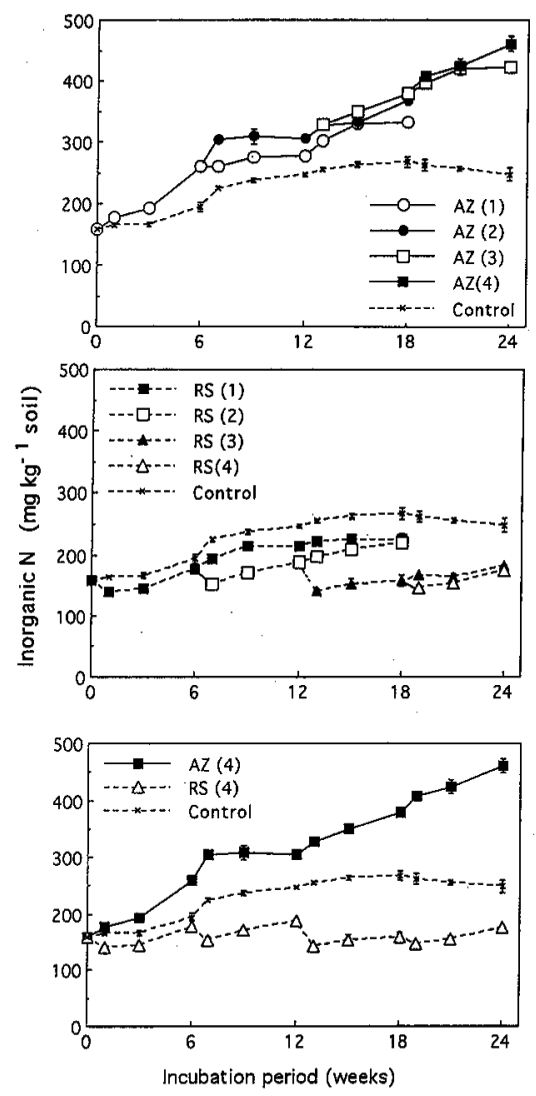

Fig. 4. N mineralization after continuous application of azolla and rice straw in soil. $\mathrm{AZ}=$ azolla, $R S=$ rice straw. The numbers (1), (2), (3), and (4) indicate the frequency of application of azolla and rice straw. Standard errors are indicated by bars or within each symbol.

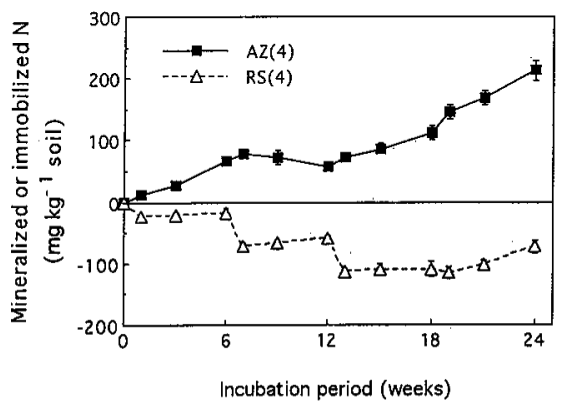

Fig. 5. Amount of $\mathrm{N}$ mineralized or immobilized from azolla and rice straw after 4 applications into soil. The amount of mineralized or immobilized $\mathrm{N}$ was obtained by subtracting the amount of inorganic $\mathrm{N}$ in the control soil from that in the amended soils. Positive and negative values in the $\mathrm{Y}$-axis indicate mineralized and immobilized $\mathrm{N}$, respectively. $\mathrm{AZ}$ (4)=azolla applied 4 times, RS (4)=rice straw applied 4 times. Standard errors are indicated by bars or within each symbol. 
a limitation in the amount of maximum biomass formation was observed in this study (Figs. 6 and 7).

\section{Changes in microbial biomass after continuous application of $0 . \mathrm{M}$}

As shown in Figs. 6 and 7, microbial biomass formation was considerably influenced by the addition of O.M. The amounts of biomass $\mathrm{C}$ and $\mathrm{N}$ increased immediately after O.M. incorporation, reached maximum values after one week of each application, and declined thereafter. A similar pattern of biomass formation was reported previously by Azmal et al. (1996a). The amount of biomass in the unamended soil also increased and became maximum one week after incubation, presumably due to some disturbance effect, such as mixing of the soil.

The level of maximum biomass formation reached a ceiling after the 2 nd application, at which the maximum biomass amount did not increase. Similar pattern of changes in the number of bacteria, fungi, and actinomycetes after repeated application of rice straw was
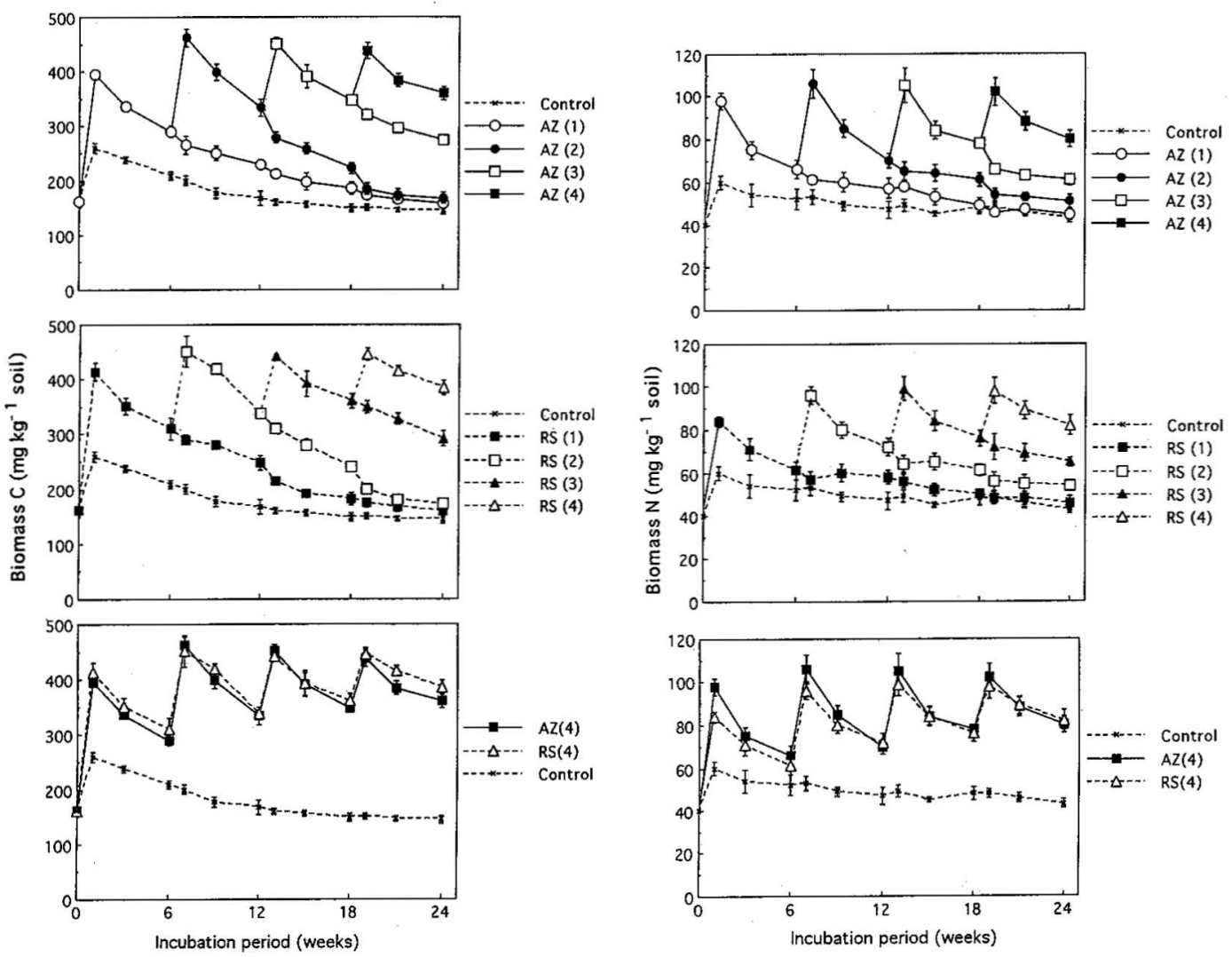

Fig. 6. Changes in the amount of microbial biomass $C$ in soil amended with azolla or rice straw. $\mathrm{AZ}=$ azolla, $\mathrm{RS}=$ rice straw. The numbers (1), (2), (3), and (4) indicate the frequency of application of azolla and rice straw. Standard errors are indicated by bars or within each symbol.

Fig. 7. Changes in the amount of microbial biomass $\mathrm{N}$ in soil amended with azolla or rice straw. $\mathrm{AZ}=$ azolla, $\mathrm{RS}=$ rice straw. The numbers (1), (2), (3), and (4) indicate the frequency of application of azolla and rice straw. Standard errors are indicated by bars or within each symbol. 
reported previously by Kai et al. (1984). The finding that the amount of maximum biomass did not increase beyond a certain level in spite of the large amount of active biomass and continuous supply of sufficient $C$ substrates may indicate that the soil has a certain capacity to hold biomass. Van Veen et al. (1985) suggested that the concentration of microbial biomass in soils is one of the soil characteristics. For example, soils with a high clay content generally contain larger amounts of microbial biomass than the soils with a lighter texture (Jenkinson 1977; Sorensen 1983). The level of maximum biomass formation in this experiment may reflect the capacity for microbial biomass of the soil we used.

Another possible reason for the limitation of biomass increase is the difference in the maintenance energy required. Since the amount of biomass immediately before the 2 nd application of O.M. was larger than that just before the 1st application (Figs. 6 and 7), a higher level of maintenance energy until the maximum biomass formation would be needed for the 2nd application. Thus, although the same amount of O.M. was applied to the soil, a smaller amount of substrates would be utilized for the synthesis of new biomass after the 2nd application, and the maximum level of biomass did not increase.

Inhibition by toxic substances may account for the limitation of biomass increase. Tate (1995) reported that under acidic conditions, organic acids are toxic to microbial growth. In the present study, a considerable amount of O.M. was applied repeatedly, which might have led to the production of organic acids in soil. However, the soil $\mathrm{pH}$ values in this study ranged from 4.5 to 5.0 throughout the incubation period. Thus, we consider that organic acid accumulation, if any, did not influence the biomass formation.

The amounts of biomass $\mathrm{C}$ and $\mathrm{N}$ increased continuously through the repeated application of azolla or rice straw when compared in a certain period after each of the applications. For example, the amount of biomass $\mathrm{N}$ six weeks after the 1st, 2nd, 3rd, and 4th applications of rice straw was $61,72,76$, and $82 \mathrm{mg} \mathrm{N} \mathrm{kg}^{-1}$ soil, respectively. This continuous increase is probably due to the residual effects of the previous applications, i.e., undecomposed components of the previously applied plant residues and microbial bodies once having been formed and then having died had accumulated in soil, which contributed to this continuous increase, suggesting that repeated application of O.M. increases the amount of microbial biomass.

\section{Effects of application of azolla and rice straw on the increase in biomass}

The amounts of biomass $\mathrm{C}$ were not significantly different between the azolla and the rice straw treatment (Fig. 6), presumably because the amount of added $C$ was adjusted in the two treatments and was not the limiting factor for microbial growth in this experiment. Meanwhile, in general, the amounts of biomass $\mathrm{N}$ were larger in the azolla treatment than in the rice straw treatment after the 1st application, and did not differ significantly between them after the 2nd, 3rd, and 4th applications (Fig. 7). The results suggest that the effects of $\mathrm{C} / \mathrm{N}$ ratio of added O.M. on biomass $\mathrm{N}$ formation disappeared after repeated application.

\section{REFERENCES}

Aoyama, M. and Nozawa, T. 1993: Microbial biomass nitrogen and mineralization-immobilization processes of nitrogen in soils incubated with various organic materials. Soil Sci. Plant Nutr., 39, 23-32

Azmal, A.K.M., Marumoto, T., Shindo, H., and Nishiyama, M. 1996a: Mineralization and microbial biomass formation in upland soil amended with some tropical plant residues at different temperatures. Soil Sci. Plant Nutr., 42, 463-473 
Azmal, A.K.M., Marumoto, T., Shindo, H., and Nishiyama, M. 1996b: Mineralization and changes in microbial biomass in water saturated soil amended with some tropical plant residues. Soil Sci. Plant Nutr., 42, 483-492

Black, C.A. 1968: Soil-Plant Relationships (2nd ed.), p. 462, John Wiley and Sons, New York

Bremner, J.M. 1965: Inorganic forms of nitrogen. In Methods of Soil Analysis, Part 2, Ed. C.A. Black, D.D. Evans, J.L. White, L.E. Ensminger, F.E. Clark, p. 1179-1237, American Society of Agronomy, Madison, WI

Brookes, P.C., Kragt, J.F., Powlson, D.S., and Jenkinson, D.S. 1985a: Chloroform fumigation and the release of soil nitrogen: The effects of fumigation time and temperature. Soil Biol. Biochem., 17, 831-835

Brookes, P.C., Landman, A., Pruden, G., and Jenkinson, D.S. 1985b: Chloroform fumigation and the release of soil nitrogen: A rapid direct extraction method to measure microbial biomass nitrogen in soil. Soil Biol. Biochem., 17, 837-842

Frankenberger, W.T., Jr. and Abdelmagid, H.M. 1985: Kinetic parameters of nitrogen mineralization rates of leguminous crops incorporated into soil. Plant Soil, 87, 257-271

Haider, J., Marumoto, T., and Azad, A.K. 1991: Estimation of microbial biomass carbon and nitrogen in Bangladesh soils. Soil Sci. Plant Nutr., 37, 591-599

Hassink, J., Lebbink, G., van Veen, J.A. 1991: Microbial biomass and activity of a reclaimed-polder soil under a conventional or a reduced-input farming system. Soil Biol. Biochem., 23, 507-513

Hirose, S. 1973: Mineralization of organic N of various plant residues in the soil under upland conditions. J. Sci. Soil Manure, Jpn., 44, 157-163 (in Japanese)

Jenkinson, D.S. 1977: Studies on the decomposition of plant material in soil V. The effects of plant cover and soil type on the loss of carbon from ${ }^{14} \mathrm{C}$ labelled ryegrass decomposing under field conditions. J. Soil Sci., 28, 424-434

Kai, H., Kawaguchi, S., Omura, S., and Aibe, T. 1984: Function of organic matter decomposition in soil. In Biseibutsu no Seitai (Ecology of the Microbes) 12, Ed. Japanese Society of Microbial Ecology, p. 3-20, Gakkai Shuppan Center, Tokyo (in Japanese)

Kanke, B. 1987: Application of the proximate analysis to soil saccharides. Jpn. J. Soil Sci. Plant Nutr., 58, 556-560 (in Japanese)

Killham, K. 1994: Soil Ecology, p. 92-93, Cambridge University Press, Cambridge, New York

Marumoto, T. 1984: Mineralization of C and N from microbial biomass in paddy soil. Plant Soil, 76, 165173

Marumoto, T., Kai, H., Yoshida, T., and Harada, T. 1974: Contribution of microbial cells and cell walls to an accumulation of the soil organic matter becoming decomposable due to the dry of soil (part 3). $J$. Sci. Soil Manure, Jpn., 45, 332-345 (in Japanese)

Sorensen, L.H. 1983: Size and persistence of microbial biomass formed during the humification of glucose, hemicellulose, and straw in soils containing different amounts of clay. Plant Soil, 75, 121-130

Tate, R.L. 1995: Soil Microbiology, p. 100, John Wiley and Sons, New York

Vance, E.D., Brookes, P.C., and Jenkinson, D.S. 1987: An extraction method for measuring soil microbial biomass C. Soil Biol. Biochem., 19, 703-707

Van Veen, J.A., Ladd, J.N., Amato, M. 1985: Turnover of carbon and nitrogen through the microbial biomass in a sandy loam and a clay loam incubated with $\left[{ }^{14} \mathrm{C}(\mathrm{U})\right]$ glucose and $\left[{ }^{15} \mathrm{~N}\right]\left(\mathrm{NH}_{4}\right)_{2} \mathrm{SO}_{4}$ under different moisture regimes. Soil Biol. Biochem., 17, 257-274 